\title{
Использование ионообменной хроматографии для получения изоферментов лактатдегидрогеназы в печени крыс
}

\author{
® 2019 Селиванова Н.В., Магулян М.Б., Моисеенко А.В., Епринцев А.Т. \\ Воронежский государственный университет, Воронеж
}

Поступила в редакцию 15.11.2019 г.

DOI: $10.17308 /$ sorpchrom.2020.20/2384

Разработанная схема очистки, включающая три последовательные стадии, позволила провести высокоэффективное разделение форм лактатдегидрогеназы из печени крысы. Получение изоферментов в высокоочищенном состоянии открывает перспективы исследования их каталитических и регуляторных характеристик. Особую важность это имеет в перспективе изучения функционирования данной ферментной системы в гепатоцитах крыс с индуцированным аллоксановым диабетом. Известно, что адаптивная реакция клеточного метаболизма к экспериментальному диабету происходит на уровне ферментных систем цикла Кребса и глиоксилатного пути. Результаты исследования регуляторных и физико-химических характеристик свидетельствуют, что выделенные из гепатоцитов крыс изоферменты ЛДГ отличаются по электрофоретической подвижности, сродству к субстрату и коферменту. Значения $\mathrm{R}_{\mathrm{f}}$ составили для ЛДГ $\Gamma_{1}-0.07$, для ЛДГ $\Gamma_{2}-0.16$ и для ЛДГ -0.25 . Ранее исследования этого фермента у гороха на нашей кафедре показали, что на электрофореграмме у данного организма при специфическом окрашивании проявляется одна полоса с $\mathrm{R}_{\mathrm{f}} 0.65$ Сродство фермента к субстрату имеет большое значение для скорости протекания ферментативного катализа, поэтому полученные в нашей работе каталитические характеристики дают возможность обосновать трансформацию путей утилизации пирувата в клетках крыс в нормальных условиях и при патологиях, вызванных экспериментальным диабетом. Наибольшей афинностью к субстрату обладает 3 изофермент $\left(\mathrm{K}_{\mathrm{m}}=0.227 \mathrm{MM}\right)$, наименьшей - ЛДГ ${ }_{1}\left(\mathrm{~K}_{\mathrm{m}}=14.104 \mathrm{mM}\right)$. Интересно, что в отличие от ЛДГ другого представителя млекопитающих - черногубой пищухи - два изофермента ЛДГ крысы показывают значительно большее сродство к пирувату. Таким образом, использование ионообменной хроматографии позволило получить три изоформы лактатдегидрогеназы из клеток печени крыс и изучить их физико-химические характеристики.

Ключевые слова: лактатдегидрогеназа, изоформы, ионообменная хроматография, электрофорез.

\section{Введение}

В последние годы биохимики достигли больших успехов в выделении и получении высокоочищенных препаратов ферментов разных метаболических путей. Большую роль в этих исследованиях играет использование хроматографических и ионообменных методов очистки белков из гомогенатов клеток растений, животных и микроорганизмов. В наших работах изучаются ферменты цикла трикарбоновых кислот, глиоксилатного шунта и других центральных метаболических путей [1].

Лактатдегидрогеназа (ЛДГ, КФ 1.1.1.27) - это один из ключевых ферментов гликолиза, который, находясь на развилке путей метаболизма углеводов, участвует в регуляции тонко сбалансированного анаэробного и аэробного гликолиза. Однако функционирование ЛДГ может быть связано не только с его центральной ролью в рециркуляции анаэробного гликолиза, но и в регуляции соотношения НАД+/ НАДН, 
поскольку именно оно влияет на скорость многих каталитических реакций. Было показано, что внутриклеточный НАД+ играет важную роль в регуляции транскрипции генов, связанных с метаболизмом и циркадианными ритмами [2]. Предполагается, что ЛДГ может участвовать в клеточном цикле [3], в регуляции активности АТФ зависимых К+ каналов [4]. Все многообразие внутриклеточных процессов, связанных определенным образом с каталитической активностью ЛДГ, предполагает необходимость изучения механизмов функционирования этого фермента у животных в норме и при различных патологиях. В связи с этим, целью работы явилось получение высокоочищенных препаратов ЛДГ из печени крыс с помощью ионообменной хроматографии и изучение их свойств.

\section{Эксперимент}

В качестве исследуемого объекта использовались самцы лабораторных крыс (Rattus norvegicus L.) в возрасте трёх месяцев и массой тела 250-270 г. Работа выполнена в соответствии с санитарными правилами для вивария и нормами гуманного обращения с лабораторными животными.

Активность фермента определяли на СФ-2000 (ЛОМО, Россия) спектрофотометрическим методом_при длине волны $\lambda=340$ нм по изменению оптической плотности, которая должна уменьшаться вследствие расходования НАДН [5]. Содержание белка в пробе определили по методу Лоури [6].

Для получения высокоочищенных препаратов ЛДГ была использована схема очистки, включающая три стадии. Все операции проводили при температуре $0-4{ }^{\circ} \mathrm{C}$. Печень гомогенизировали, после чего осуществляли дифференциальное центрифугирование в два этапа на центрифуге Eppendorf Centrifuge 5804 (5 минут при 3000g, а затем $11000 \mathrm{~g}$ в течение 30 минут). Гель-фильтрацию проводили на колонке $(1.5 \times 20$ cм), заполненной сефадексом G-25 («Pharmacia», Швеция) для освобождения от низкомолекулярных примесей. Ионообменную хроматографию проводили на колонке $(1.5 \times 12$ см) с ДЭАЭ-целлюлозой («Whatman», Англия). Элюцию осуществляли линейным градиентом $\mathrm{NaCl}$ от 20 до 500 мМ.

Электрофоретические исследования белков проводили в 7.5\% полиакриламидном геле [7]. Для специфической идентификации ЛДГ использовали тетразолиевый метод со средой следующего состава: 50 мМ Tris-HCl буфер (pH=7.8), 0.1 М

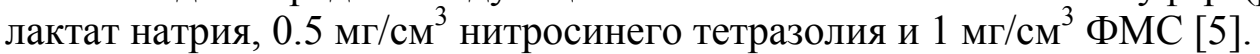

\section{Обсуждение результатов}

С помощью электрофореза в 7.5\% ПААГ с последующим специфическим окрашиванием на активность ЛДГ в печени крыс были обнаружены три изоформы фермента с различной электрофоретической подвижностью (рис.1). Множественные формы ЛДГ были описаны ранее, распределение изоферментов в различных животных тканях неоднозначно в результате переменной экспрессии генов А и В [9].

Для получения гомогенного препарата ЛДГ из печени крыс была проведена трехстадийная очистка, результаты которой представлены в табл. 1. После элюции белков с ДЭАЭ-целлюлозы линейным градиентом $\mathrm{NaCl}$ (20 до 500 мМ) нами были получены три предполагаемых изофермента лактатдегидрогеназы при концентрациях 200, 300 и 400 мМ хлорида натрия. Для ЛДГ 1 удельная активность составила 11.08 Е/мг белка, выход - 11.01\%, степень очистки - 16.06 раз. ЛДГ 2 имела следующие показатели: удельная активность - 11.50 Е/мг белка, выход - 6.42\%, степень очистки - 16.67 раз. И, наконец, для ЛДГ з величина удельной активности составила 19.14 Е/мг белка, а выхода и степени очистки - $16.75 \%$ и 27.74 раза соответственно. 
Таблица 1. Очистка лактатдегидрогеназы из печени крыс $(\mathrm{n}=3, \mathrm{p}<0.05)$

\begin{tabular}{|c|c|c|c|c|c|c|c|}
\hline \multicolumn{2}{|l|}{ Стадия очистки } & $\begin{array}{l}\text { Объём, } \\
\mathrm{cm}^{3}\end{array}$ & $\begin{array}{c}\text { Активность, } \\
\text { Е }\end{array}$ & $\begin{array}{c}\text { Белок, } \\
\text { мг }\end{array}$ & $\begin{array}{c}\text { Удельная } \\
\text { активность, } \\
\text { Е/мг белка } \\
\end{array}$ & $\begin{array}{l}\text { Выход, } \\
\quad \%\end{array}$ & $\begin{array}{l}\text { Степень } \\
\text { очистки }\end{array}$ \\
\hline \multicolumn{2}{|l|}{ Гомогенат } & 25 & 25.11 & 36.24 & 0.69 & 100 & 1 \\
\hline \multicolumn{2}{|l|}{$\begin{array}{c}\text { Гель-фильтрация } \\
\text { на сефадексе G-25 }\end{array}$} & 4.0 & 19.00 & 22.71 & 0.84 & 75.67 & 1.21 \\
\hline \multirow{3}{*}{$\begin{array}{c}\text { Ионообменная } \\
\text { хроматография на } \\
\text { ДЭАЭ-сефацеле }\end{array}$} & 1 & 2.0 & 2.77 & 0.25 & 11.08 & 11.01 & 16.06 \\
\hline & 2 & 2.0 & 1.61 & 0.14 & 11.50 & 6.42 & 16.67 \\
\hline & 3 & 2.0 & 4.21 & 0.22 & 19.14 & 16.75 & 27.74 \\
\hline
\end{tabular}

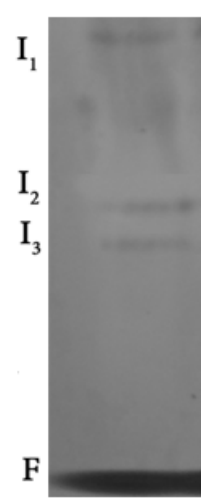

Рис. 1. Изоферментный состав лактатдегидрогеназы в гепатоцитах крыс.

$\mathrm{I}_{1-3}$ - изоформы 1-3 (ЛДГ, ЛДГ, ЛДГ ${ }_{3}$, $\mathrm{F}-$ фронт красителя.

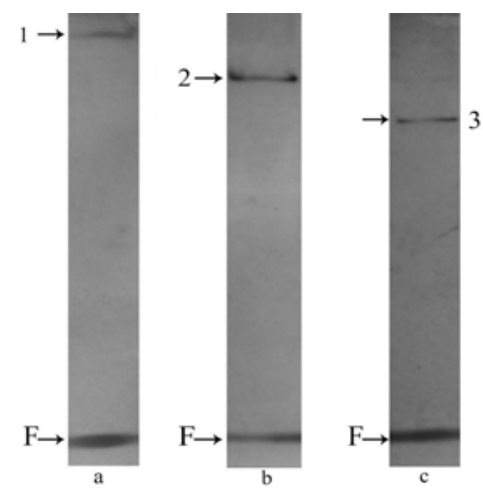

Рис. 2. Электрофореграммы специфического проявления лактатдегидрогеназы очищенных препаратов из печени здоровой крысы (Rattus norvegicus L.): $\mathrm{a}-$ ЛДГ 1 ; - ЛДГ $;$ c-ЛДГ $;$ F-фронт красителя; 1 - полоса белка с $\mathrm{R}_{\mathrm{f}}=0.07$; 2 -полоса белка с $\mathrm{R}_{\mathrm{f}}=0.16 ; 3$ - полоса белка с $\mathrm{R}_{\mathrm{f}}=0.25$

Важнейшим этапом очистки является ионообменная хроматография на ДЭАЭ-целлюлозе, позволившая получить исследуемый фермент в высокоочищенном состоянии.

Полученные после проведенной многоступенчатой очистки фракции исследовали с помощью электрофореза в полиакриламидном геле с последующим проявлением на активность с нитросиним тетрозолием в присутствии лактата в качестве субстрата. Результаты типичных электрофореграмм представлены на рис. 2, из которых видно, что каждая из выделенных фракций обладала лактатдегидрогеназной активностью, о чем свидетельствует наличие четко выраженной темно-синей полосы формазана (продукта восстановления НСТ).

Получение гомогенных препаратов ЛДГ позволило провести сравнение их кинетических характеристик. Исследование $K_{\mathrm{m}}$ показало, что все изоформы фермента подчиняются кинетике Михаэлиса - Ментен. Константы Михаэлиса для исследуемых форм ЛДГ имели следующие значения для восстановления пирувата: 14.104 мМ для ЛДГ, 1.788 мМ для ЛДГ 2 и $0.227 \mathrm{мM}$ для ЛДГ. Анализ данных говорит о том, что максимальное сродство к пирувату имеет ЛДГ $\Gamma_{3}$ а минимальное ЛДГ ${ }_{1}$. Значения $\mathrm{K}_{\mathrm{m}}$ по НАДН составили $2.577 \mathrm{мM}$ для ЛДГ $\Gamma_{1}, 0.455 \mathrm{мM}$ для ЛДГ 2 и 0.084 мМ для ЛДГ . Следовательно, наибольшим сродством к данному коферменту отличается также ЛДГ, а наименьшим - ЛДГ.

Таким образом, выделенные и очищенные до гомогенного состояния изоформы обладают разным сродством к субстрату. Анализ литературных данных катали- 
тических свойств различных форм лактатдегидрогеназы из других организмов свидетельствуют, что данный энзим также подчиняется кинетике Михаэлиса-Ментен, но значения $\mathrm{K}_{\mathrm{m}}$ разнообразны. Так, исследуемый показатель ЛДГ, выделенной из Escherichia coli, составляет 1.91 мМ для пирувата [10], а из Litopenaeus vannamei 203 мкМ по пирувату и 23.4 мкМ по НАДН [11], константа Михаэлиса по пирувату для формы, выделенной из икроножной мышцы крысы, характеризуется значением 0.229 мМ [12]. Варьирование значений сродства фермента к субстрату может объясняться специфическими особенностями организма, из которого выделялась лактатдегидрогеназа.

\title{
Заключение
}

Таким образом, была разработана эффективная схема очистки ЛДГ из печени крыс, включающая ионообменную хроматографию. Полученные в гомогенном состоянии препараты лактатдегидрогеназы позволяют изучить кинетические характеристики этого важнейшего фермента клеточного метаболизма. Получение изоферментов в высокоочищенном состоянии открывает перспективы исследования их каталитических и регуляторных характеристик. Особую важность это имеет в перспективе изучения функционирования данной ферментной системы в гепатоцитах крыс с индуцированным аллоксановым диабетом.

\section{Список литературы}

1. Епринцев А.Т., Попов В.Н., Шевченко М.Ю. Глиоксилатный цикл: универсальный механизм адаптации? М. ИКЦ «Академкнига». 2007. 228 с.

2. Nikiforov A, Kulikova V, Ziegler M. // Crit Rev Biochem Mol Biol. 2015. Vol.50. No 4. pp. 284-297.

3. Bilan D.S., Matlashov M.E., Gorokhovatsky A.Y., Schultz C. et al. // Biochim Biophys Acta. 2014. Vol.1840. No 3. pp. 951-957.

4. Raph S.M., Bhatnagar A., Nystoriak M.A. // Chem Biol Interact. 2019. Vol. 305. pp 21-27.

5. Секерина Е.M. // Химия и химическая технология : тезисы научно-технической выставки-конференции ХТИ. Екатеринбург, 2013. С. 8. Режим доступа: http://elar.urfu.ru/handle/10995/21648

6. Lowry O.H., Rosebrough N.J., Farr A.L., Randall R.J. // J. Biol. Chem. 1951. Vol. 193. pp. 265-275.
7. Davis B.J. // Ann. N.Y. Acad. Sci. 1994. Vol. 121. pp. 404-427.

8. Avezov K., Reznick A.Z., Aizenbud D. // Arch Oral Biol. 2014. Vol. 59. pp.142-148.

9. Beebee T.J., Carty D.S. // Biochem J. 1982. Vol. 205. No 2. pp. 313-320.

10.Jiang T., Xu Y., Sun X., Zheng Z. et al. // Protein Expr Purif. 2014. Vol. 95. pp.219-225

11.Fregoso-Peñuñuri A.A., Valenzuela-Soto E.M., Figueroa-Soto C.G., Peregrino-Uriarte A.B. et al. // Protein Expr Purif. 2017. Vol. 137. pp. $20-25$

12.Халилов Р.А., Джафарова М.А., Мейланов И.С. // Известия вузов. СевероКавказский регион. 2011. № 1. С. 76-78.

13.Аль Дайни Саба Хади, Сыромятников М.Ю., Гати Моханнад Абдулраззак Гати, Епринцев А.Т.// Вестник ВГУ. Серия: Химия. Биология. Фармачия. 2012. № 1 С. 176181.

\section{Using ion exchange chromatography to obtain the lactate dehydrogenase of rat liver}

\author{
Selivanova Natalia V., Magulyan Marina B., \\ Moiseenko Alexandr V., Eprintsev Alexandr T. \\ Voronezh State University, Voronezh
}

A purification scheme has been proposed, consisting of three successive stages, which makes it possible to conduct a highly effective separation of forms of lactate dehydrogenase from rat liver. Obtaining 
isoenzymes in a highly purified state opens up prospects for the study of their catalytic and regulatory characteristics. This is of particular importance for the future study of the functioning of this enzyme system in the hepatocytes of rats with alloxan-induced diabetes. It is known that the adaptive reaction of cellular metabolism to experimental diabetes occurs at the level of enzyme systems of the Krebs cycle and the glyoxylate pathway.

The results of the study of regulatory and physico-chemical characteristics indicate that LDH isoenzymes obtained from rat hepatocytes differ in electrophoretic mobility and affinity to the substrate and coenzyme. The $\mathrm{R}_{\mathrm{f}}$ values were 0.07 for $\mathrm{LDH}_{1}, 0.16$ for $\mathrm{LDH}_{2}$, and 0.25 for $\mathrm{LDH}_{3}$. Earlier studies of this enzyme in peas carried out by the researchers from our department have shown that the electrophoregram of this body with a specific staining shows a single band with $\mathrm{R}_{\mathrm{f}}$ equal to 0.65 .

The affinity of the enzyme towards the substrate is of great importance for the rate of enzyme catalysis. Therefore, the determined catalytic characteristics allow us to justify the transformation of the way pyruvate is utilized in the cells with pathologies caused by experimental diabetes as compared to normal rat cells. The highest affinity to the substrate was observed in third isoenzymes $\left(\mathrm{K}_{\mathrm{m}}=0.227 \mathrm{mM}\right)$ and the lowest in $\mathrm{LDH}_{1}\left(\mathrm{~K}_{\mathrm{m}}=14.104 \mathrm{mM}\right)$. Interestingly, unlike the LDH of another mammal, the black-lipped pika, the two isoenzymes of rat $\mathrm{LDH}$ have a much higher affinity to pyruvate.

Thus, ion-exchange chromatography was used to obtain three lactate dehydrogenase isoforms from rat liver cells and to study their physical and chemical characteristics.

Keywords: lactate dehydrogenase, isoforms, ion-exchange chromatography, electrophoresis

\section{References}

1. Eprintsev A.T., Popov V.N., Shevchenko M.Yu. Glyoxylate cycle: universal adaptation mechanism? M. ICC "Akademkniga", 2007, $228 \mathrm{p}$.

2. Nikiforov A, Kulikova V, Ziegler M., Crit Rev Biochem Mol Biol., 2015, Vol. 50, No 4, pp. 284-297.

3. Bilan D.S., Matlashov M.E., Gorokhovatsky A.Y., Schultz C. et al., Biochim Biophys Acta, 2014, Vol. 1840, No 3, pp. 951-957.

4. Raph S.M., Bhatnagar A., Nystoriak M.A., Chem Biol Interact., 2019, Vol. 305, pp 21-27.

5. Sekerina E.M., Chemistry and chemical technology: abstracts of scientific and technical exhibition-conference of khti. Ekaterinburg, 2013, pp. 8. Mode of access: http://elar.urfu.ru/handle/10995/21648

6. Lowry O.H., Rosebrough N.J., Farr A.L., Randall R.J., J. Biol. Chem., 1951,. Vol. 193, pp. $265-275$

Селиванова Наталия Владимировна - к.б.н., доцент кафедры биохимии и физиологии клетки, Воронежский государственный университет, Воронеж, тел.(473)2208877

Магулян Марина Борисовна - студент кафедры биохимии и физиологии клетки, Воронежский государственный университет, Воронеж

Моисеенко Александр Владимирович - аспирант кафедры биохимии и физиологии клетки, Воронежский государственный университет, Воронеж

Епринцев Александр Трофимович - д.б.н., проф., зав. кафедрой биохимии и физиологии клетки, Воронежский государственный университет, Воронеж, тел.(473)2208877
7. Davis B.J., Ann. N.Y. Acad. Sci., 1994, Vol. 121, pp. 404-427.

8. Avezov K., Reznick A.Z., Aizenbud D., Arch Oral Biol., 2014, Vol. 59, pp.142-148.

9. Beebee T.J., Carty D.S., Biochem J., 1982, Vol. 205, No 2, pp. 313-320.

10.Jiang T., Xu Y., Sun X., Zheng Z., Ouyang J., Protein Expr Purif., 2014, Vol. 95, pp.219225

11.Fregoso-Peñuñuri A.A., Valenzuela-Soto E.M., Figueroa-Soto C.G., Peregrino-Uriarte A.B. et al., Protein Expr Purif., 2017, Vol. 137, pp. $20-25$

12. Khalilov R.A., Jafarova M.A., Meylanov I.S., Izvestiya vuzov. The North Caucasus region, 2011, No 1, pp. 76-78

13. al Daini Saba Hadi, Syromyatnikov M.Yu., Gati Mohannad Abdulrazzak Gati, Eprintsev A.T., Vestnik VSU, Series: Chemistry. Biology. Pharmacy, 2012, No 1. pp. 176-181.

Selivanova Natalia Vladimirovna - Ph.D of Biology, docent of Department of Biochemistry and Physiology, Voronezh State University, Voronezh, E-mail: kir2202@yandex.ru

Magulyan Marina B. - student of Department of Biochemistry and Physiology, Voronezh State University, Voronezh

Moiseenko Alexandr V. - Ph. D. student of Department of Biochemistry and Physiology, Voronezh State University, Voronezh

Eprintsev Alexander T. - Doctor of Biology, head of Department of Biochemistry and Physiology, Voronezh State University, Voronezh, E-mail: bc366@bio.vsu.ru 